\title{
Innovations for Teaching Forensic Science in Modern Russian Transitive Society
}

\author{
Anastasia Kovaleva ${ }^{1 *}$, Elena Frolova ${ }^{2}$ \\ ${ }^{1}$ Don State Technical University, department "Criminal Law and Criminalistics", 344000 \\ Rostov-on-Don, Russian Federation \\ ${ }^{2}$ Southern Federal University, "Criminal Law and Forensic Science", 344000 Rostov-on- \\ Don, Russian Federation
}

\begin{abstract}
Contemporary society inevitably demands modernisation of the conventional approach to education in general, and to teaching specific disciplines in particular. Forensic science is a special legal science, because it has its own objectives, is closely connected with virtually all existing branches of science and technology, and its knowledge is of applied nature. With the European standard of education being implemented during the transitional period of this country, Russian universities face the objective necessity not only to change the attitude to the teaching process but also to ensure a qualitative modernisation of the way the accumulated knowledge is transmitted to students. Conventional methods and means of teaching proved by decades of experience are no longer enough to efficiently form students' competences required for practical work. There is now the objective necessity not only to teach innovative activity but also to apply it in the teaching process.
\end{abstract}

\section{Introduction}

A transitive society is basically a society facing a transitional period of development, during which society is moving into a new, different qualitative state, the one that has never existed before. A traditional new society under formation is usually called the open society [1]. At the same time, almost all scholars relate this transitive process with an innovative process, sometimes referred to as an 'innovation burst'.

This process also affected such important area of human life as education. Unlike any others, this area is inextricably linked to accumulation of information, its use and transmission from generation to generation. For quite a lengthy period, this process was

\footnotetext{
* Corresponding author: nastya-161@yandex.ru
} 
implemented through theoretical lectures and seminars, conventional textbooks, tutorials, lecture notes, etc. However, some scholars rightfully note that a transitive society seeking a higher level of development - the level usually referred to as the open society-is also characterised by cognizing humans seeking to add innovations into their knowledge and culture [2].

Thus, it becomes evident that the transitive period of societal development is inextricably linked to the process of creating and implementing innovations, as both phenomena involve a qualitative transition to a new state. Neither process can be comfortable, as they both imply abandoning the settled, habitual and comfortable conditions of existence, taking the risk and assuming more responsibility. At the same time, they both embody the idea of development - which, by the way, will not necessarily be a positive one.

The new open society is only possible if we build the kind of a civil society, where the whole system of emerging relations offers incentives to comprehensive development of a personality and its creative potential. All this brought about the objective necessity to change the existing model of academic knowledge and to put the whole system of education onto a new foundation, suitable for the needs of the post-industrial stage of societal development.

The above-mentioned trends manifested themselves in Russia's joining the Bologna Process. Due to the latter, education ceased to be a public good it used to be in a closed, totalitarian, society. Hence the key task: to raise the quality of the education provided. In the given case, the quality level is primarily measured by how demanded the educational services are in that particular society. The quality of student training is correlated with the level of assimilation of competences which imply knowledge of not just the terminology, but also the methodology and systematic correlations in this particular field [3].

\section{Results and discussion}

Improving law-enforcement staff training methods is objectively impossible without raising the level of knowledge in forensic science. Especially noteworthy is the fact that such knowledge must reflect the latest achievements in various fields of science and technology that are somehow or other related to solving and investigating crimes.

There are two criteria that serve as determining factors here:

1. Russia's purposeful movement towards European standards of education-which is fully in line with joining the Bologna Process;

2. Along with the above-mentioned, preservation of the best Russian traditions based not only on the system of education that functioned before and was efficient enough but also on specific regional features typical of the work of law-enforcement bodies.

The current level of human development is characterised by the fact that the knowledge we have acquired get stale very fast. This forces the system of education not only to provide students with extensive training but also to teach them how to replenish and refresh their knowledge and abilities when needed. The Bachelor's level, lasting from 3.5 to 4 years, aims at training qualified lawyers: professionals with a wide creative potential in any branch of law and advanced cognitive skills [4]. At this stage of forensic knowledge formation, the learning process can be limited to general theory of the given discipline and to general provisions of methodological basics of investigating particular crimes.

But although the Bachelor's programme represents complete higher education and although a Bachelor can apply for the relevant staff positions in law-enforcement bodies, this degree clearly seems insufficient. And the judgement is not based on assumptions of university professors, it is practice-driven.

The second level of training, the Master's programme, provides deeper and more focused knowledge, including the one in forensic science. As the Master's degree means a 
larger scope of forensic knowledge, the number of academic hours and the course programme itself should be different. The Master's level implies that the learning material should be extended to include investigation tactics and methods of investigating particular crimes. Besides, forensic science can be studied in a broader way, with special supplementary courses being added. They would focus on methods of investigating crimes that are typical of that particular region or are the most common ones in local lawenforcement practice.

Moreover, the Master's programme can also include a course in a narrower field which would be directly aimed at further employment in the relevant profession. As an illustration, let us take the experience of the Law Faculty of the Wroclaw University, Poland. The faculty provides post-graduate courses for those who want to work as RTA experts or documentation analysts. Noteworthy, internship (the 'application') is mandatory for all lawyers who plan to work in the judicial system, public prosecutor's offices, the Bar or the notary system [5].

After acquiring a narrower specialisation, Masters will have the right to continue their education as post-graduate students, to pursue research work, to investigate grave crimes or to create and implement innovative research methods.

Taking a closer look at how forensic science is taught, we should note that people traditionally relate it with European education, as the significance of this science was recognised and described a long time ago by famous European legal experts, such as Gross, Reiss, Hellwig and others. The latest trends, however, indicate that forensic science is gradually being ousted from general curricula of virtually all universities. The process looks all the stranger in Austria and Germany, the two countries regarded as the birthplace of this science [6].

US, Austrian, German and Swiss universities either teach forensic science as an optional discipline or do not teach it at all. This often results in students from these countries choosing curricula of Western European universities for specialised training in forensic science.

As a state which keeps quite close ties with neighbouring regions, Russia has a certain potential in this respect. Thus, countries from the CIS, Southeast Asia, the Middle East and Europe or even countries from other continents can be regarded as potential recipients of the service in question. In terms of the teaching of forensic science, we can consider preparation of special curricula for foreign students, which would include theoretical and methodological basics of forensic tactics and technique.

As for the teaching process itself, we should, too, examine characteristic features of forensic science as a discipline. It is only by using various kinds of information in the learning process that a higher level can be achieved in assimilation of the material and in the students-professor communication. It is hardly a secret for anyone that different people have different ways of assimilating the same information: some retain easier the things they heard, others - the things they saw, still others - the things they wrote down themselves. Therefore, it is certainly reasonable to use various forms to deliver the material, as it makes the learning process more efficient. Objectively speaking, if all human senses are involved in the learning process, assimilation of the material will improve dramatically. All this explains the reasons why it is necessary and wise to use advanced informational technology in education.

Among the forms of informational technology used in education, multimedia rightfully takes a central place. Material cannot be presented in such form unless the professor is able to rethink creatively the goal of each particular lesson within the whole course and to skillfully design and work out a scenario for that lesson considering its topic. A multimedia course is ready when it is more than just a set of images and sounds. It should be a coherent system of delivering information; the one that, in a way, anticipates students' potential 
questions and train of thought on the given material; the one that interacts with the students and is sure to give a feedback to how they are assimilating the information.

The effect that a multimedia application will yield in the learning process depends on a number of factors, e. g.:

- what technical conditions there are for the course;

- how the course corresponds to the level of education, the stage of learning the discipline, and the goal of the lesson;

- how the contents of the course conform to didactic requirements;

- to what extent the teaching staff are ready and able to take a creative approach when working out the course.

It should also be noted that forensic science takes a special place in the system of legal sciences. Clearly, the applied nature of this science is among the main reasons that make it so special. Hence one of the primary objectives of forensic science: to give students the knowledge, ability and skills to apply the achievements of other sciences to detecting, documenting, seizing and examining the evidence, and to use them efficiently in the criminal procedure. It is evident that one cannot transmit the required information and transform it into assimilated knowledge without modelling a specific situation or reproducing specific actions.

Moreover, law-enforcement officers see informational technology steadily ousting conventional methods they use daily for preventing, solving and investigating crimes. Naturally, all this immediately affects, or sometimes even determines, the development of forensic science, setting new tasks for the professors:

1. to be perfectly aware of the capabilities of the latest scientific and technical tools employed by the Ministry of Internal Affairs, and to be able to use them;

2. to know technical features and capabilities of the innovative scientific and technical tools that law-enforcement officers can potentially use in practice;

3. to settle issues relating to the use of scientific and technical achievements in the learning process - concerning both the discipline as a whole and each particular topic.

Evidently, solving tasks 1 and 2 is closely connected with the interaction between the learning process and practice of particular law-enforcement agencies and units. This implies the use of software to explore the options of solving their tasks. Such software includes specialised programmes (Sonda, Papilon, Portrait, Photofit, Firearms, etc.) and general-purpose programmes - for example, MS Office elements or various graphic and text editors.

Solving task 3 correlates with transmitting information to the students, making demonstrations, giving explanations, etc.

At the current stage, there are two main groups of programmes which can be used and are widely used for teaching forensic science:

1. Controlling or training/controlling programmes consisting of test assignments. They certainly make the professor's work easier, as they assess the results basing on a preset algorithm. There is, however, a reverse side to it. It is often the case that even the training-mode assignments only demonstrate the right and wrong answers without explaining the essence, though this is what students need to assimilate this or that topic, process or phenomenon. Students, in their turn, tend to do the assignments mechanically instead of reaching deep into the matter; their only aim is to pass the test.

2. Latest multimedia applications containing various branches of science, lectures, consultations and practical assignments. In fact, the whole course can be made of such material. But there are, unfortunately, very few programmes of that kind, on either forensic science or other disciplines. The existing ones include Fingerprinting by the Voronezh State University, a multimedia textbook by A. G. Filippov, and a course of 
multimedia lectures by the Chair of Forensic Science, Didorenko Academy of Internal

Affairs, Luhansk (Forensic Registration, Firearms, Investigative Examination Tactics).

\section{Conclusions}

We currently deliver our forensic science course using programmes from group one and also some of the specialised software which allows to make virtual examination of the scene and virtual search in various types of environment.

Apart from that, so-called forensic testing grounds are created at higher education institutions so that students can practice certain skills in detection, seizure, packaging, examination and assessment of proofs, as well as investigation tactics. A testing ground like this is just a space which can be transformed for practicing the above-mentioned activities and forming the required competences.

Summing up, we would like to point out that the use of innovative technology for teaching forensic science is currently one of the topical tasks. It has a huge potential to make the educational process more efficient, which, in the long run, will inevitably result in a more efficient operation of national law-enforcement bodies.

\section{References}

1. Henri Bergson, Les Deux Sources de la morale et de la religion (The Two Sources of Morality and Religion) / Transl. from French,. - p. 288; Moscow: Kanon, 1994)

2. K. R. Popper, The Open Society and Its Enemies / Ed. by V. N. Sadovsky - Vol. 1: The Spell of Plato, 251 (Moscow: Feniks, International Foundation 'Cultural Initiative', 1992)

3. S. Akhiezer, How to "Open" a Closed Society: Issues of Open Society Formation in Russia, 40 (Moscow: Magistr, 1997)

4. O. B. Tomilin, A. V. Brittov, S. I. Dyomkin, Educational Technology Forming Competences in the System of Professional Higher Education // University Management: Practice and Analysis, 1, 114 (2005)

5. V. Bakhtin, N. Karpov, L. Mynzatu. Forensic Training of Future Lawyers: Competences Relating to Paedagogy or Forensic Science // Law and Life, 8, 14-17 (2003)

6. E. Kurapka, G. Malevski, R. Burda. Teaching Forensic Science Levels at a Lithuanian Legal University // Current Issues of Theory and Practice of Criminal Proceedings and Forensic Science. Part 2, 33 (Moscow. 2004) 